\title{
Parents' Perception of Child Rearing as a Gender Issue in Marital Relationship: Implications to Social Health
}

\author{
Anthonia U. Ejifugha \\ Department of Physical and Health Education \\ Alvan Ikoku Federal College of Education \\ Owerri-Nigeria
}

\section{Doi:10.5901/mjss.2013.v4n5p61}

\begin{abstract}
The study was conducted to determine parents' perception of child rearing as a gender issue in marital relationship in Imo State: implications to social health. It focussed on gender issues in education of children,.training in home management, emotional health, family relationship, and religious upbringing. The descriptive research design was used to present parents' perception of gender issues in child rearing in marital relationship. The results of the study were used to decipher the social health implications in family settings. The population of the study constituted of child rearing parentswithin thearea of study. The sample was 120 parents randomly sampled from four selected towns of the Local Government Area which was basically an urban setting. A questionnaire was used for data collection. The study revealed that gender issue sin children education demahd that both parents should take responsibility for children education (72\%). Both should be involved in the discipline of the children (54\%). Fathers should teach children masculine home chores. Both should teach the children emotional stability (57.5\%), to love (62.5\%), be respectful (60\%), and should inculcate self acceptance in children (54\%). Both should take responsibility for their religious upbringing. Mothers should teach them effective communication (42\%).).Fathers have less emotional toles yhan mothers The study revealed that gender of respondents influenced their perception of parental responsibilities in the education and dev[opment of emotional health of children. It was recommended that parents should define their parental roles in marriage instead of generating issues that affect the social health of their children.
\end{abstract}

\section{Introduction}

Nigeria is one of the most densely populated countries in Africa with varieties of cultures which influencemarriage and child rearing. Every Nigerian is a product of his cultural background and ethnic diversity. Hence child rearing is a major parental responsibility that generate gender issues Child rearing is synonymous with child upbringing which is a developmental task confronting every adult male and female. Hence the curiousity of the researcher is to articulate gender issues generated by child rearing in marital relationship and their implications to social health in Imo State of Nigeria which is the cultural background that formed the geographical framework of the study.

Child rearing encompasses all behaviours that those in parenting engage in to foster the development of the child during which they inculcate skills, ethical values and wisdom of a particular culture that will optimally be manifested in adulthood. Child rearing is a parental responsibility in whichlife skills, norm, values, and behavioural patterns of the family are inculcated to youths in Imo State. These roles are culturally and socially determined because they are rarely seen as a sole responsibility of any single parent or both but that of the community. An adage maintains that every child who is well raised is the pride of the community but a bad child is the child of his parents. This is the cultural reason for reporting misdemeanours or conducts of every child or adolescent to the parents who have authority over his life. 
Gender is defined as a society constituted role and responsibilities of men and women within a given culture or location (Adisokam, 2009). It is a set of characteristics that distinguish male from female. The discriminating characteristics vary from sex to social roles to gender identity (Graldas, Johnso, Percy and Ratner, 2010). Gender is a system of roles and responsibilities that are not biologically determined but determined by the social, political and economic contexts of the individual. It is a process in which individuals who are born into biological categories of men and women become the social categories of male and female through the acquisition of locally defined attributes of masculinity and femininity beyond biological differences. Virtually all other differences between male and female are socially constructed and culturally biased. This is why the geographical location of the study is pertinent in determining the gender issues of a particular community.

An issue refers to facts, behaviours, actions, phenomena, factors, forces, prejudices and situations which are currently filled with controversy, debate and dissension and for which consensual agreement on the solution of the specific matter is lacking yet there are reasonable projections, predictions, prescription or speculations on what should happen or be done as they relate to the matter in question. Gender issues are facts, behaviours, action, factors, forces prejudices and solutions that control and determine the roles of male and females in the society as they perform their daily duties. Generally an issue presents the following characteristics:

i. It is topical and may be persistent for a long time.

ii. It generates controversy.

iii. It lasts for a longtime and there is no consensual agreement.

iv. Concerned public may be interested and they may in the majority or minority.

v. It is relative to a particular society.

vi. It may negatively affect social, political or economic order of a society.

vii. It is often open to questioning.

viii. It is transient it; it may be alive today and tomorrow is dead tomorrow.

ix. The resolution of an issue elicits action from the affected society.

(Meziobi, 1996; Ejifugha 2003)

Child rearing which is optimally a parental responsibility generate gender issues in such areas as whose responsibility among couples to train children in school, home management, developmment of emotional health, interpersnal relationship and religious upbringing. This is a consequence of evolutionary trend that has penetraed traditional family settings to thwart the traditional roles of fathers and mothers. This trend seems to have revotionalised parental responsibilities in the domestic realm as determined by social, political and economic status of families to generate gender issues in marital relationships. The traditional roles of parents in homes have been drastically altered. Many men are not very capable of being solely the bread winners of their homes. Even when they are, some prefer to focus on capital projects while the women feed the families and engage in serious masculine tasks that take them outside the home for a long time on daily basis. Child rearing is an emerging gender issue in Imo State as a result of controversies and role conflicts between parents in the execution of their roles in child rearing; hence the problem of the study. Most men shift their traditional roles to women, and the latter being more attached to their children carry multiple roles.

The study stemmed from domestic roles that generate arguments, discords, and controversies among couples that deter thier interpersonal relationship. Parental roles for males include: providee for the family, do not show emotion, must make decisions, must never accept infertility as his fault, etc. For women, they must cook food, rear and care for the children, must be emotional and sensitive, must give in to sexual advances and must be obedient to decisions taken by the man no matter what, With cultural transition in every realm of life, what is the status of male-female roles in the domestic realm.?The curiosity of the researcher is to elucidate the contemporary perception of parental responsibilities in child rearing. The result of the study will project the roles that generate gender issues in the domestic realm as well as their implications to social 
health of families in Imo state of Nigeria. The purpose of the study is to determine gender issues in child rearing among parents in Imo State of Nigeria and their implications to social health. The study specifically focused on gender issues in education of children, training in home management, emotional development, sound interpersonal relationship and religious upbringing.

\section{Research Questions}

What are the gender issues generated by

1. Training children in school?

2. training children in home management?

3. development of emotional health of children?

4. development ofinterpersonal relationship in children?

5. religious upbringing of children?

6. Does gender of parents influence their perception of responsibility in child education?

7. Does gender of parents influence their perception of responsibility in emotional health?

\section{Hypotheses}

1. Gender does not influence parents' perception of their responsibilities in education of their children

2. Gender does not influence parents' perception of responsibility towards emotional development of their children

\section{Method of Study}

The descriptive research design was used to present parents' perception of gender issues in child rearing in marital relationship.. The population of the study constituted of all child rearing parents in Owerri North LGA of Imo State. The sample of the study constituted of 120 child rearing parents randomly sampled in four selected towns of the Local Government which was basically an urban setting.

A thirty-five item questionnaire was developed for the study. The face validity of the instrument was established by three jurors. Test-retest reliability was applied and it yielded a correlation coefficient of 0.91 using Spearman Rank Order correlation co-efficient. The instrument was administered on face to face basis.Data collated from the research instrument were analyzed using descriptive and inferential statistics.

\section{Results}

Table 1. Gender issues in Education of Children

\begin{tabular}{llcccc}
\hline & Education of Children & Father & Mother & Both & Total \\
\hline 1. & Train the children in school & $36(30 \%)$ & $12(10 \%)$ & $72(60 \%)$ & $120(100 \%)$ \\
2. & Payment of school fees & $72(60 \%)$ & $35(29.2 \%)$ & $11(9.3 \%)$ & $120(100 \%)$ \\
3. & Transport the children to and from school & $35(29.2 \%)$ & $34(28.3 \%)$ & $51(42.5 \%)$ & $120(100 \%)$ \\
4. & Purchase their text books and instructional materials & $63(52.5 \%)$ & $15(12.5 \%)$ & $42(35 \%)$ & $120(100 \%)$ \\
5. & Provide school clothes and foot wears & $49(40 . \%)$ & $36(30 \%)$ & $35(29.2 \%)$ & $120(100 \%)$ \\
6. & Pay their school fees and other levies & $65(54.2 \%)$ & $22(18.3 \%)$ & $33(27.5 \%)$ & $120(100 \%)$ \\
7. & Help in their homework after school & $27(22.5 \%)$ & $58(48.3 \%)$ & $35(29.2 \%)$ & $120(100 \%)$ \\
\hline
\end{tabular}


Table 1 shows that both should take responsibility for their education (72\%) transport them to school (42\%). Fathers should pay childre's of school fees (60\%), purchase their school books (52\%) and school attire (40\%). Mothers should be responsible for their homework after school (48\%).

Table 2: Parents Responsibilities in Home Management Training

\begin{tabular}{llcccc}
\hline & Home management & Father & Mother & Both & Total \\
\hline 7. & Purchase of kitchen equipment & $17(13.7 \%)$ & $78(65 \%)$ & $25(20.8 \%)$ & $120(100 \%)$ \\
8. & Train house cleanliness & $13(10.8 \%)$ & $17(14.2 \%)$ & $90(75 \%)$ & $120(100 \%)$ \\
9. & Train children in doing home chores & $17(19.2 \%)$ & $89(74.1 \%)$ & $11(14.8 \%)$ & $120(100 \%)$ \\
10. & Train in laundry & $39(32.5 . \%)$ & $28(23.3 \%)$ & $57(47.5 \%)$ & $120(100 \%)$ \\
11. & Teach children ironing & $74(61.6 \%)$ & $18(15 \%)$ & $28(23.3 \%)$ & $120(100 \%)$ \\
12. & Washing of car & $78(65 \%)$ & $22(18.3 \%)$ & $23(19.2 \%)$ & $120(100 \%)$ \\
13. & Discipline of children & $17(14.2 \%)$ & $38(31.7 \%)$ & $65(54.2 \%)$ & $120(100 \%)$ \\
\hline
\end{tabular}

Table 2 Mothers should take responsibility for the purchase of kitchen equipment (65\%) train in home chores (60\%). Both should be involved in the discipline of the children (54\%), house cleaning and laundry (39.2\%).. Fathers should teach children ironing (61\%), washing of car (65\%),

Table 3: Emotional Development in Children

\begin{tabular}{llcccc}
\hline & Emotional Development & Father & Mother & Both & Total \\
\hline 14. & Teach love to Children & $10(8.3 \%)$ & $35(29.2 \%)$ & $75(62,5 \%)$ & $120(100 \%)$ \\
15. & Teaches effective communication & $10(8.3 \%)$ & $51(42.5 \%)$ & $59(49.2 \%)$ & $120(100 \%)$ \\
16. & Give attention to children & $15(12.5 \%)$ & $50(41.7 \%)$ & $41(34.2 \%)$ & $120(100 \%)$ \\
17. & Inculcate Self confidence in children & $17(13.7 \%)$ & $64(53.3 \%)$ & $41(34.2 \%)$ & $120(100 \%)$ \\
18. & Teach emotional stability & $16(13.6 \%)$ & $35(29.2 \%)$ & $69(57.5 \%)$ & $120(100 \%)$ \\
19. & Teach children to be respectful & $18(15 \%)$ & $30(25 \%)$ & $72(60 . \%)$ & $120(100 \%)$ \\
20. & Inculcate in the achild acceptance & $11(9.2 \%)$ & $34(28.3 \%)$ & $65(54.12 \%)$ & $120(100 \%)$ \\
\hline
\end{tabular}

Table 3 reveals that both should teach the children to love (625\%) teach emotional stability $(57.5 \%)$ teach children to be respectful (60\%) and inculcate self acceptance in a child (54.1\%). Mothers should teach effective communication (49.3\%), give more attention to children (41.7\%), inculcate self confidence in children (53.3\%). Fathers have no dominant emotional responsibility.

Table 4. Parental Responsibility towards Relationship in the Family

\begin{tabular}{llcccc}
\hline & Emotional Development & Father & Mother & Both & Total \\
\hline 21. & Spend more time with the children & $17(14.2 \%)$ & $62(51.2 \%)$ & $41(34.2 \%)$ & $120(100 \%)$ \\
22. & Instills trust in a child & $28(23.3 \%)$ & $30(25 \%)$ & $62(51.2 \%)$ & $100(100 \%)$ \\
23. & Teach children relationship skills & $16(13.3 \%)$ & $47(39.2 \%)$ & $57(40.8 \%)$ & $100(100 \%)$ \\
24. & Communicate more with Children & $9(7.5 \%)$ & $95(73.3 \%)$ & $57(40.8 \%)$ & $120(100 \%)$ \\
25. & Care of the children & $16(5 \%)$ & $35(29.2 \%)$ & $16(13.3 \%)$ & $120(100 \%)$ \\
26. & Should take children out & $36(30 \%)$ & $19(15.8 \%)$ & $65(54.2 \%)$ & $120(100 \%)$ \\
27. & Ensure unity in the home & $12(10 \%)$ & $25(20.8 \%)$ & $85(69.2 \%)$ & $120(100 \%)$ \\
28. & Help a child choose His/her friend? & $7(5.8 \%)$ & $34(28.3 \%)$ & $71(49.2 \%)$ & $120(100 \%)$ \\
\hline & 0 & & & \\
\end{tabular}


From the table above, mothers should spend more time with the children (51.2\%), communicate with the children (73.3\%) teach children relational skill (40.8\%). Both should instill trust in a child (51.2\%) take care of childrenl (65.8\%), take children out (54.2\%) help a child chose his or her friend(49.2\%).

Table 5. Parental Responsibility towards Religious Upbringing

\begin{tabular}{clcccc}
\hline & Emotional Development & Father & Mother & Both & Total \\
\hline 29. & Instruct the child on religious principles & $40(33.3 \%)$ & $22(18.8 \%)$ & $48(40 \%)$ & $120(100 \%)$ \\
30. & Conduct prayer at home & $19(15.8 \%)$ & $29(24.2 \%)$ & $72(60 \%)$ & $120(100 \%)$ \\
31. & Ensure that children learn about God & $36(30 \%)$ & $19(15.8 \%)$ & $59(48.3 \%)$ & $120(100 \%)$ \\
32. & Bible expositions in the home & $20(16.7 \%)$ & $25(20.8 \%)$ & $68(56.7 \%)$ & $120(100 \%)$ \\
33. & Helps to build a child's faith in God & $20(16.7 \%)$ & $40(33.32 \%)$ & $53(44.2 \%)$ & $120(100 \%)$ \\
34. & Contributes mostly in the Salvation of he child & $15(12.8 \%)$ & $43(35.8 \%)$ & $60(50 \%)$ & $120(100 \%)$ \\
35. & Watch over the spiritual growth of the child & $8(6.7 \%)$ & $39(32.5 \%)$ & $63(52.5 \%)$ & $120(100 \%)$ \\
\hline
\end{tabular}

From the table above, both should instruct religious principles (40\%), conduct prayers at home (60\%) ensures that children learn about God (48\%) conduct scriptural exposition at home (56.7\%), help build a child faith in God (44.2\%), contribute mainly in children salvation (60\%) and watch over the spiritual growth of the child (52.5\%).

Table 6. Gender of parents and perception of responsibility in child education.

\begin{tabular}{|c|c|c|c|c|c|}
\hline Gender & \multicolumn{5}{|c|}{ Parental Roles } \\
\hline & Father & Mother & Both & Neither & Total \\
\hline Male & 20 & 17 & 13 & 12 & 62 \\
\hline Female & 14 & 13 & 16 & 15 & 58 \\
\hline Total & 34 & 30 & 29 & 27 & 120 \\
\hline
\end{tabular}

Does gender of respondents influence their perception gender issues in the education of children. Chjsquare calculated value $=2.07$. Chj-square t-tab $-7.815, \mathrm{df}=3$, level of sig. 0.05 . Since the table value is greater than the calculated value the null hypothesis is rejected which states that gender of respondentts does not influence the perception of gender issuesin the education of children.

Table 7. Does gender of parents influence their perception of gender issues in the in emotional health?

\begin{tabular}{|c|c|c|c|c|c|}
\hline Gender & Father & Mother & Both & Neither & Total \\
\hline Male & 21 & 17 & 22 & 10 & 70 \\
\hline Female & 17 & 18 & 13 & 2 & 50 \\
\hline Total & 38 & 35 & 35 & 12 & 120 \\
\hline
\end{tabular}

Table 7 shows Chi-square analysis on the influence of gender on the perception of influence their perception gender issues in the emotional health of their children. Chj-square Cal value $=4.87, \mathrm{Chj}$ squaretab $=7.815, \mathrm{df}=3$, level of sig $=0.05$. The hypothesis that gender of respondentts does not influence the perception of gender issues on the development of health of the children is rejected. 


\section{Discussion of Results}

Education was defined by essentialist as the transmission of what is worthwhile to those committed to it.Traditionally in Nigerian cultural setting, the transmission of culture is the responsibility of parents and the community. It defined the gender roles of the traditional agent to whom that was entrusted to. Hence education of children has been a joint responsibility of both parents,

Gender roles identify both sexes as male and female while biological roles identify them as man and woman, categorizing them male and female creates a barrier and either is compelled to identify with his/her gender or become an object of mockery in the society. This is because each gender is identified with social expectations that define the behaviour appropriate for each sex. Although the specific nature of responsibilityn and their degree of differences vary, they always favour men (Palan, 2001),

The study found that gender roles that generate isusues in marital relationship in the education of children encompass: payment of school fees, purchase of school attire and book were defined to be masculine while assistance in home work is a feminine role. This is still influenced by purchasing power as the gender defined roles of females were to be home makers. Susie, Hoffman, Joanne, Theresa and Zena (2004) maintained that the most recently gender inequality has been located in women's responsibility for social reproduction of labour force. This implies that women are needed primarily to bear and rear the next generation of workers and to keep the current labour force well fed and motivated.

Gender issue arising from this misconception of roles is that women undermine their futuristically appreciated roles of labour providers and their currently admired roles of motivators of the labour force of every nation. Women's role, though undervalued in the capitalistic society, can only be maximized when. they are opportuned to earn income for their families. Earning subsistent income enhances their self esteem and self actualization. The study confirms that both should take responsibility in children's education. Gender issue is generated in a family when the male abandons his roles in the education of education and willfully shifts it over to the female. Even when the latter carries the burden, instead of the male appreciating the complementary roles of female he feels threatened in his position as the head of the family. On the other hand, when female puts on a superiorly complex because of her predominant role in this area, conflict is generated.

Myle (2003) argued in as much as women are allowed to earn income for the family, this limitation engender gender conflict and generate issues. In families were roles are clearly defined from the onset, or where there are mutual agreement on changing roles of the gender, children are given the opportunity for role modeling, this precisely is the social health implication. Children are modeled at home, to take responsibilities for education of their wards from their homes; they must apply some in their homes.ehys view was corrobgrated by Adler, Boyce, Chesney, Folkman, and Syme,. (1993).

Emotion is defined as a feeling that is private and subjective; it is a state of psychological arousal, an expression or display of distinctive somatic and automatic responses. They are atoms deemed as defending or attacking in response to a threat (http/library/thinkquest.org). Emotional health is the degree to which you feel emotionally secured and relaxed in everyday life. An emotionally healthy person has an open mind, a relaxed body and an open heart, it lead to success in work, relationship and health (http/www/chow.com/about).

From this perspective, development of emotional stability in children is the duty of the family which promotes family health. Edelman and Mandle (2002) reported a study in Ohio to identify ways in which economically disadvantaged families with young children, defined family health within household content.Families defined family routines as patterns affected by the community.Mothers played key roles as health leaders, caregivers, and gate keepers in family health. One of the implications of the study was developing family- focussed care models in which mothers are pivotal. This buttresses the unrefutable fact that mothers are closer to the children than fathers in family health and family life, economic demands withstanding (Arkutu, 1995) Development of a child's emotion and emotional health should not actually 
become a gender issue in family health.Both male and female have roles to play which can only be enhanced Each partner in marriage should focuss attention on his/her role and do it well.

Adeleye and Chiwuzie (2007) maintained that some traditional domestic roles in child upbringing encompassed child rearing, provision of food, good housing, fetching of firewood, and better clothing, purchasing for the family, laundry were all responsibilities of motherhood. There traditional roles when undertaken by men attract ridicule from the community to the male partner. On the contrary, earning fat salary by a woman does not attract ridicule. This is the nexus of gender issues.

\section{Summary of results}

- Both should take responsibility for children education (72\%) transport them to school (42\%). Fathers should pay childre's of school fees (60\%), purchase their school books (52\%) and school attire (40\%). Mothers should be responsible for their homework after school (48\%).

- Mothers should take responsibility for the purchase of kitchen equipment (65\%) train in home chores (60\%). Both should be involved in the discipline of the children (54\%), house cleaning and laundry (39.2\%).. Fathers should teach children ironing (61\%), washing of car (65\%),

- Both should teach the children to love (625\%) teach emotional stability (57.5\%) teach children to be respectful (60\%) and inculcate self acceptance in a child (54.1\%). Mothers should teach effective communication (49.3\%), give more attention to children (41.7\%), inculcate self confidence in children (53.3\%). Fathers have less dominant emotional responsibilities than mothers..

- Mothers should spend more time with the children (51.2\%), communicate with the children (73.3\%) teach children relational skill (40.8\%). Both should instill trust in a child (51.2\%) take care of childrenl (65.8\%), take children out (54.2\%) help a child chose his or her friend(49.2\%).

- Both should instruct religious principles (40\%), conduct prayers at home $(60 \%)$ ensures that children learn about God (48\%) conduct scriptural exposition at home (56.7\%), help build a child faith in God (44.2\%), contribute mainly in children salvation (60\%) and watch over the spiritual growth of the child (52.5\%).

The null hypotheses that gender of respondents does not influence parents' perception of gender issues in the education of children and development of emotional health of the children are rejected.

\section{Conclusion}

The study concluded that education of children is a joint responsibility of both parents, training in home management is their role with specific functional areas. Fathers have less dominant emotional responsibility than mothers in marriage. Both are predominantly responsibke for grooming children in famipy relationship and religious upbringing.Social health implication is that whatever role modelling parents exhibit is what children adopt because the home is a training ground for gender issues addressed in this study It is recommended that parents should define their marital responsibilities before settling down in marriage. Parents should redefine their roles in the course of marriage developmentahd play down gender issues. Social health is dratiscally affected by gender issues in marriage both for children and adults.

\section{References}

Adeleye, O.A. \& Chiwuzie, (2007). He does his own and walks perceptions about male attitudes and practices regarding safe motherhood in. Ekeadolar, Southern Nigeria Afr. J. Reproduction Health 11:76-89

Adesokan F.O. (2000). Reproduction health for all ages. Ado-Ekiti, Ekiti State, Ekiti State, faxwell Nigeria Ltd

Arokiasary, P. (2002). Gender preference, Contraceptive use and fertility in India. Regional and development influence. Int. J. popul Geogr, 8 (1): 49-67. 
Adler, N.E, Boyce, W.T., Chesney, M.A. Folkman, S.\& Syme, S.L. (1993). Socioeconomic inequalities in health: No easy solution. Journal of American Medicine Association. 269: 3140-3145.

Arkutu, A.A. (1995). Healthy women, healthy mothers (2nd eds) New York: Family Care Internal Inc.

Adisokan,.P. (2002). Gender preference, Contraceptive use and fertility in India. Regional and development influence. Int. J. popul Geogr,8 (1): 49-67.

Galdas, P.M. Johnson, J.L. Percy, M.E. \& Ratner, P.R. (2010). Help seeking for cardiac symptoms: Beyond the masculine-feminine binarySocial Science \& Medicine 71; 1-18-24.

Edelman, C.L. \& Mandle C.L. (2002). Health Promotion throughout the life span (5th ed) Philadelphia: Mosby Inc

Ejifugha, A.U. (2006). Equipping the health teacher, Owerri Publisher. Danny publishing Company.

Myra Max Ferce (1987). Analyzing Gender a handbook of social science research Newbury:: California sage.

Palan, K. (2001). Gender identity in consumer research: A literature review and research agenda. Academy of marketing science review.

Susie, H, Joanne, M. Thereza \& Zena S. (2004). The future of the female condom. In Patricia Oonoran, Frances A. Althaus (eds), International Family Planning Perspectives New York: Alan Guttmacher Institute

What is emotion: http/library/thinkquest.org relieved 24/10/2012.

Wierzbricka, A. (1992) Defining Emotion Concepts Cognitive science 16, 539-581. 